\title{
The relationship between a market orientation and financial performance in South African organisations
}

\author{
S.S. Loubser \\ Graduate School of Business, University of Stellenbosch. P.O. Box 610. Bellville. 7535 South Africa
}

Received March 2000

\begin{abstract}
Organisations are in constant flux and with pow erful universal trends such as globalisation. technological discontinuity. deregulation and new competencies within a continuously changing environment, both business leaders and academics are searching for new insights into organisational dynamics. In recent years more and more academics have suggested that a market orientation should be considered as a business philosophy and/or business behaviour that will lead to better business performance. However. not much research has been done on this organisational phenomenon and it is not well understood. Market orientation has been defined in this study as the business culture that is focused on creating mutually rewarding relationships between customers and the organisation based on a foundation where (1) the interests of all stakeholders are actively pursued: (2) competitive advantage is based on the organisation's ability to learn from the market itself. and to mobilise core competencies in response: (3) a set of beliefs exists that puts the customer's interests first: and (4) processes exist that suppon this belief. This study differs from previous empirical research on market orientation in that it takes a systemic view of market orientation. rather than a cause-effect view. It considered 449 unlisted and 51 listed organisations. and found that a market orientation leads to better financial results. Also. market orientation is a necessary. but maybe not sufficient. condition for business excellence. and further research needs to be done in this regard.
\end{abstract}

\section{Introduction}

Why do some organisations underachieve and even fail? One explanation is that industries, and therefore companies, that have enjoyed years of protected prosperity, are suddenly confronted with powerful universal trends such as globalisation, technological discontinuity, deregulation and new competencies. These trends have resulted in higher levels of competition, products and services of a higher quality at lower or stable prices, and an oversupply of products and services generally. Simultaneous to this, two other trends have become irreversible. Firstly, the demographic and lifestyle patterns of people are changing, and secondly, the demands of all stakeholders of the organisation are becoming increasingly pertinent. Each stakeholder group. albeit customers, employees, shareholders, suppliers or environmental pressure groups, is better organised and determined to get their priorities attended to. Organisations that are successful in adjusting to this changing environment, are more likely to survive and prosper. From this follows that organisations are clearly complex and management often find that multidimensional, rather than unidimensional solutions, are required.

This brings into question how to obtain the optimal balance between an organisation's philosophy and its behaviour. In this regard market orientation has increasingly been studied in recent years as an approach to improving business outcomes. More and more academics have been suggesting that a market orientation should be considered as a business philosophy and/or business behaviour that will lead to better business financial performance.

This study was undertaken to establish, for South African organisations, the nature of market orientation and its impact on financial outcomes. Simultaneously, it endeavoured to determin whether market orientation is a philosophical or behavioural element in the company.
First. a review of the literature on market orientation will be reported, resulting in the formulation of a market-orientation typology. Secondly. an outline of the methodology followed in this empirical research will be given. as well as the results obtained. Based on the results of the research, a new paradigm of market orientation will be presented. Lastly. the implications for management and academics alike of this new paradigm will be discussed.

\section{Literature review \\ Defining market orientation}

Kohli \& Jaworski (1990: 6) define market orientation as the organisation-wide generation of market intelligence pertaining to current and future customer needs, dissemination of the intelligence across departments. and organisation-wide responsiveness to it. This definition focuses on specific activities or behaviours, rather than philosophical notions. It facilitates the operationalisation of the market-orientation construct.

Narver \& Slater (1990: 21) define market orientation as the organisation culture that most effectively and efficiently creates the necessary behaviour for the creation of superior value for buyers and, thus, continuous superior performance for the business. According to them, market orientation consists of three behavioural components, namely: customer orientation, competitor orientation and interfunctional co-ordination: and two decision criteria - long-term focus and profitability.

Both these definitions reflect on market orientation as business behaviour. According to Tuominen \& Möller (1996 1162 ) market orientation as business behaviour can be viewed as market information processing and interfunctional co-ordination of market-related information. This view can be seen as a resource-based approach to market orientation. The resource-based approach characterises organisations as 
'heterogeneous bundles of resources and rent seekers, aiming their strategies at obtaining superior performance in the form of Ricardian rents' (Olavarrieta \& Friedmann, 1999: 217).

However, market orientation is often associated with the term philosophy. The terms orientation, philosophy, approach to management, focus, a common starting point and strategic perspective, are often used in describing marketing orientation (Brown, 1987: 25; Dreher, 1994: 153; Tuominen \& Möller, 1996: 1166). In fact, market orientation is often seen as the driving force behind the mission, values and behaviour of the organisation (Lichtenthal \& Wilson, 1992: 201-206). According to Tuominen \& Möller (1996: 1166), market orientation as a business philosophy emphasises an organisationwide philosophical perspective guiding the norms and attitudes and ultiminately the activities, behaviour and business performance.

\section{Market orientation and organisation culture}

Organisation culture has been widely described and researched. Such descriptions and definitions are often similar to the words used to describe market orientation. According to Deal \& Kennedy (1982: 14) culture reflects the dominant values espoused by an organisation, while Pascale \& Athos (1981) explain culture in terms of the philosophy that guides an organisation's policy towards employees and customers.

A useful description of culture came from Quinn (1988: 66) who defines it as the set of values and assumptions that underlie the statement, 'this is how we do things around here'. This view suggests that business philosophy are clearly and directly linked to business behaviour. This view is supported by Webster \& Deshpandé (1990: 3) who see organisation culture as the pattern of shared values and beliefs that helps individuals understand organisational functioning, and thus serves as norms for their behaviour within the organisation.

It can thus be concluded that corporate culture is distinct from an enumerative rationalist approach advanced by best managerial practice (Peters \& Waterman, 1982), but rather an interpretative paradigm in understanding the behaviour of organisations (Wilkens, 1983; Kilmann, 1985; Schein, 1985).

In the literature, market orientation is seen as a cultural issue. For example, Swartz (1990: 6) states that a market orientation involves the set of culture and behavioural issues relating to the goals and philosophies of the organisation, while Narver \& Slater (1990: 21) see market orientation as the culture that most effectively and efficiently creates the necessary behaviours for the creation of superior value for buyers.

\section{Market orientation and the learning organisation}

According to Garvin (1993: 80-81) a learning organisation is skilled at creating, acquiring and transferring knowledge, as well as modifying its behaviour to reflect new knowledge and insights. This definition from Garvin reflects five activities present in learning organisations: systematic problem solving; experimentation with new approaches; learning from their own experience and past history; learning from the experiences and best practices of others; and transferring knowledge quickly and efficiently throughout the organisation.
This learning process generally consists of four phases, namely: information acquisition, information dissemination, shared interpretation, and response (Kohli \& Jaworski, 1990: 6; Sinkula, 1994: 36; Slater \& Narver, 1995: 65). However, a more important implication of this learning process is that there are certain interrelationships between these concepts. Senge (1990) and Argyris (1977) describe two types of organisational learning. Adaptive learning is the most basic form of learning and occurs within a set of recognised and unrecognised constraints that reflects the organisation's assumption about its environments and itself. Generative learning occurs when the organisation is willing to question long-held assumptions about its mission, customers, capabilities or strategy. It requires the development of a new way of looking at the world based on an understanding of the systems and relationships that link key issues and events. Systems thinking disciplines the organisation to focus on interrelationships and dynamic processes of change rather than on linear cause-effect chains (Senge, 1990; Olavarrieta \& Friedman, 1999: 226).

Based on their research over the years, Slater \& Narver make a critical point:

'A narrow construction of market orientation could lead to learning only within traditional boundaries. To be a powerful foundation for a learning organisation and provide the opportunity for generative learning, the scope of market orientation must include all stakeholders and constituencies that (1) possess, or are developing knowledge that has the potential to contribute to the creation of superior customer value or (2) are threats to competitive advantage. The conception of market should be broadened to encompass all sources of relevant knowledge and ideas pertaining to customers and customer value creating capabilities' (1995: 68).

\section{Relationship between market orientation and organisa- tion performance}

According to Olavarrieta \& Friedmann (1999: 215), four types of resources appear to be more likely to influence organisation performance. They are: market orientation; organisational learning; organisational innovativeness; and reputational assets. They state further that a marketorientation culture contributes to an organisation's performance through knowledge-based resources such as imitation capability, market-sensing capability and organisational innovations; as well as reputational resources such as brand equity organisation image.

However, the relationship between market orientation and organisation performance has been conceptualised and empirically researched mainly in terms of business factors. The literature suggests that for business the overriding objective in a market orientation is profitability, or economic wealth.

Various measurements have been used to assess the relationship between market orientation and business performance. This includes measurements such as retum on assets (Narver \& Slater, 1990); return on investment (Hooley, Lynch \& Shepherd, 1990); profitability, size, market share and growth (Deshpandé, Farley, Webster et al., 1993); return on investment, new product success and sales growth (Greenley, 
1995); and Hunt \& Morgan (1995) who add superior quality, efficiency and innovation.

In both conceptual and empirical work certain environmental contingencies or conditions have been identified that moderate, that is increase or decrease, the strength of the relationship between market orientation and business performance. For example: market turbulence, technological turbulence, competition and the general economy (Kohli \& Jaworski; 1990: 14-15); competitive intensity (Lusch \& Laczniak, 1987); speed of changes in customer needs (Hooley et al., 1990) structural resistance (Lichtenthal \& Wilson, 1992); and organisational age and experience (Sinkula, 1994).

\section{A market-orientation typology}

An organisation is clearly a complex organism consisting of many elements or dimensions. The purpose of an organisation is to create value for all its stakeholders in whichever form this becomes relevant. An organisation cannot be explained in terms of linear or cause-effect relationships of its dimensions, although some sub-components of the organisation might be explained in such a manner.

From the literature it can be deducted and derived that the following scenarios should be included in a system describing market orientation:

- Behaviour, in the context of market orientation, is interpreted within the philosophy of the learning organisation.
This behaviour can be described as information generation, information dissemination and responsiveness to information.

- Market orientation is that focus of the business philosophy that determines the behaviour of the organisation.

- The business philosophy of the organisation is stable to the extent that the leadership quality of top management will support its integrity, but flexible or unstable to the extent that the business outcomes demand a shorter-term priority for change or maintenance.

- From this interpretation of the literature it is deducted that market orientation cannot and should not be described as either a philosophy or behaviour. It can be seen either as both, or as the reason why a certain philosophy results in certain behaviour. Market orientation should therefore not be seen as a defined activity within the organisation, but as a focus or value or orientation that has an impact on 'how things are done here'. It therefore becomes part of, not only the behaviour and business philosophy of the organisation, but of its culture. This view brings a complexity to understanding market orientation that will only be understood by considering the systemic interrelationships between all relevant organisational dimensions. Figure 1 provides a systematic flow model reflecting the inter relationships between dimensions.

Figure 2 provides definitions of the system elements in the system reflected in Figure 1.

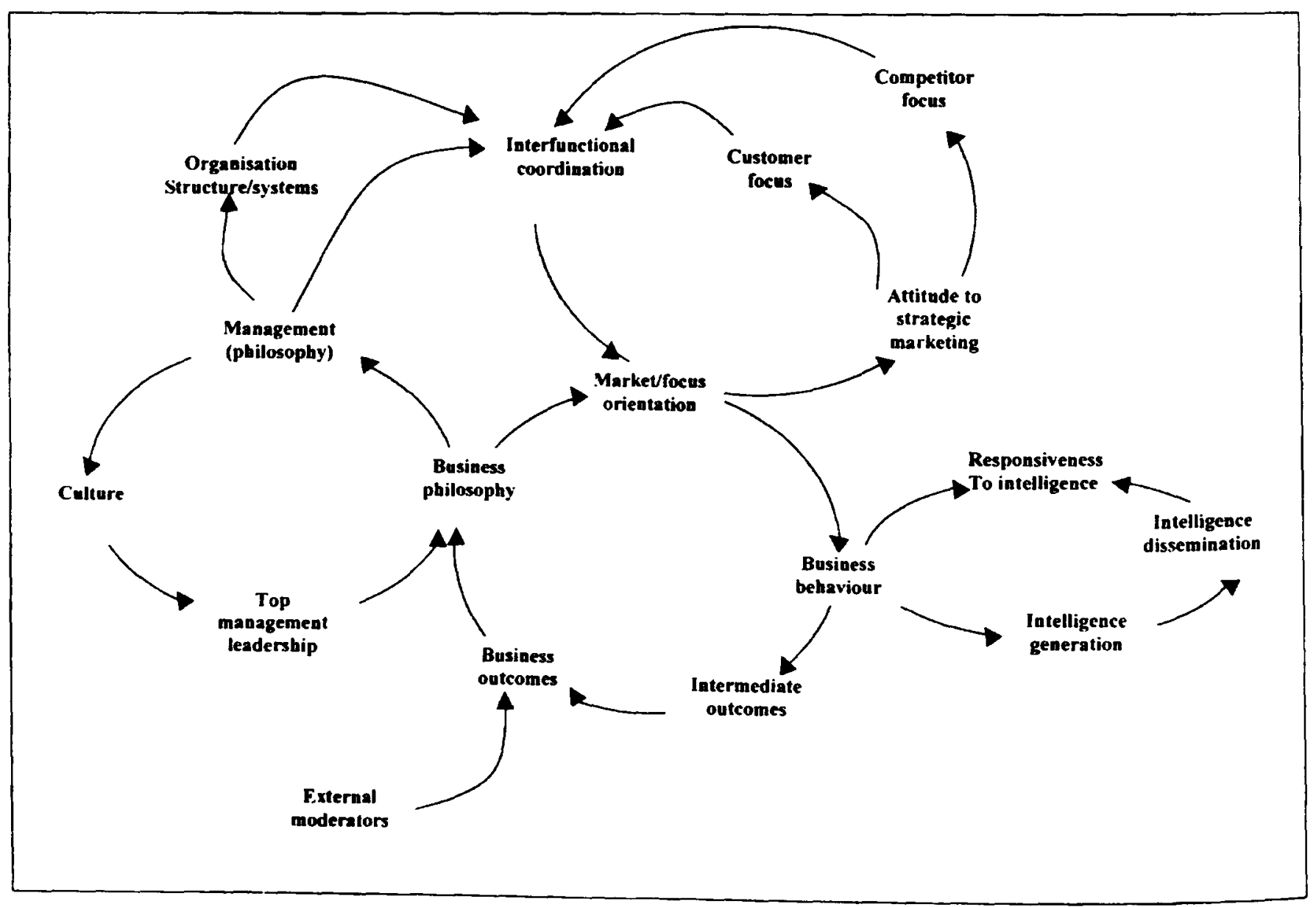

Figure 1 Market orientation in an organisational system 


\begin{abstract}
Market focus/orientation
This is the business culture that is focused on creating mutually rewarding relationships between customers and the organisation, based on a foundation where (1) the interests of all stakeholders are actively pursued; (2) competitive advantage is based on the organisation s ability to learn from the market and itself, and to mobilise core competencies in response: (3) a set of beliefs exists that puts the customer's interests first; and (4) processes exist that support this belief

Interfunctional co-ordination This is the extent to which organisational resources, including any individual in any function, are utilised and co-ordinated in creating superior value for customers and stakeholders in general.

Attitude to strategic marketing This is the extent to which the principles of the marketing concept is included in determining the strategic direction of the organisation.

Competitor focus This is the extent to which the organisation understands the short-term capacities and strategies of the key current and potential competitors.

Customer focus

This is the extent to which the organisation understands the target market buyers in order to create superior value for them continuously

Organisation structure and systems

Business behaviour

Intelligence generation

Intelligence dissemination

Responsiveness to intelligence

Business philosophy

Management philosophy

Organisation culture

Top management leadership

Business performance

Intermediate performance

Performance moderators (external variables)

This is the extent to which the organisation's structures and systems enable departments, functions and individuals to effectively create superior value for customers and other stakeholders in terms of formalisation, centralisation, specialisation and departmentalisation

This is the extent to which the organisation is able to acquire, understand, disseminate and react to relevant information about markets as the ir learning competency.

This is the extent to which the organisation finds, accumulates and analyses market intelligence pertaining to customers, competitors and other stakeholders on a formal and informal basis

This is the extent to which market intelligence is communicated, shared and understood in people in the organisation across departmental and functional borders.

This is the extent to which the organisation responds to the market intelligence that is generated and disseminated.

This is the extent to which the organisation believes that business excellence is achieved by focusing on markets, and setting strategic direction and actions towards meeting the needs of the market.

This is the extent to which the organisation behave according to three critical characteristics, namely: (1) information on all important buying influences permeates every corporate function; (2) strategic and tactical decisions are made interfunctionally and interdivisionally; and (3) divisions and functions make well co-ordinated decisions and integrate them with a sense of commitment

This is the unifying focus in the organisation that places the highest priority on the profitable creation and maintenance of superior customer value while considering the interests of other stakeholders; and provides norms for behaviour regarding the organisational development for and responsiveness to market information.

This is the extent to which top management of the organisation puts emphasis on a market orientation and demonstrates a willingness to take risks in order to encourage the organisation to be responsive to customer and stakeholder needs

This is the extent to which the organisation has a long-term profitability focus and achieves its key corporate goals

This is the extent to which the organisation creates value for its customers, employees, shareholders, leading to financial performance.

These are the factors which may influence business performance either directly or indirectly regardless of individual organisation characterisation.
\end{abstract}

Figure 2 Constructs of the organisation sy stem to which market orientation belongs

\section{Research}

The research conducted to test the systemic model of market orientation, consisted of two phases.

In Phase 1 an item pool and preliminary questionnaire were constructed. This was done from the literature, focus groups from business and individual academic inputs. A total of 335 items were initially produced, varying from 6 to 32 items per dimension. Eventually, 121 items were retained, varying from 4 to 11 items per dimension. In Phase 1 the preliminary questionnaire was administered to an effective 449 non-listed companies, across nine industry sectors and nine provinces. While the questionnaire complied with the normal scientific requirements, the sample was representative of the South African economic distribution.

This process resulted in three outcomes:

- An instrument, consisting of 97 items, or questions, were derived.

- It was concluded that market orientation was better described as part of the organisation system than as an iso- lated phenomenon.

- There is a significant relationship between the organisation system characterised by market orientation, business philosophy and business behaviour, and performance.

The purpose of this first phase, or study, was to construct the final item pool explaining the organisation system of market orientation.

In Phase 2, the main purpose was to establish the relationships between market orientation and financial performance. From the sample of listed companies, 51 were included in the final sample, representative of the various categories included.

It was decided to restrict this phase of the study to listed companies, because of the need for and availability of financial data, in order to measure the relationship between market orientation and financial performance.

Sixteen economic categories were included, namely:

- beverages, hotels and leisure

- building and construction 
- chemicals, oils and plastics

- clothing, footwear and textiles

- pharmaceutical and medical

- engineering

- food

- furniture, household and allied

- media

- motor

- packaging and printing

- paper

- electronics and electrical

- steel and allied

- stores

- transportation

Altogether $58.8 \%$ of the 51 companies are situated in the Gauteng province, $21.6 \%$ in the Western Cape and $9.8 \%$ in both Eastern Cape and KwaZulu-Natal.

Altogether $37.3 \%$ of the 51 companies have more than 3000 employees, $37.2 \%$ have between 400 and $3000 \mathrm{em}$ ployees and $25.5 \%$ have less than 400 employees.

Using the Chi-Square Goodness of Fit test, the sample was found to be distributed and representative of its population.

\section{Causal relationships between dimensions in the systemic perspective of market orientation}

The structural equation modelling (SEM) technique was used to study relationships between variables. The relationships are typically assumed to be linear and between observed and latent (or unobserved) variables. SEM is usually viewed as a confirmatory rather than exploratory procedure. It is used to assess the relative validity of alternative causal models drawn by the researcher (Bolten, 1989: vi). It cannot, itself, draw causal arrows in models or resolve causal ambiguities.

Various constructs were tested, using the Structural Equation Modelling Module, SEPATH, in the STATISTICA software package. The starting construct was the systemic representation of market orientation as shown in Figure 1 . In this construct market orientation is dependent on business philosophy, while business behaviour depends on both market orientation and business philosophy. From the goodness of fit statistics it was concluded that this model does not fit the data.

It become apparent that by combining some of the originally stated dimensions, a better fit between model and data can be obtained. Thus the best fit was obtained between the dimensions of philosophy and behaviour. In this instance philosophy is made up of market orientation and business philosophy, while business behaviour refers to the dimensions defined in the conceptual model. Figure 3 shows this model.

In this causal construct business behaviour is the result of the philosophy embodied in the organisation. Business behaviour itself can be observed in the way the organisation

- shares customer information within the context of their culture and interfunctional co-ordination;

- stays close to the customer/market to generate adequate information and to understand it well;

- shares available information across functional boundaries: and

- reacts to market needs.

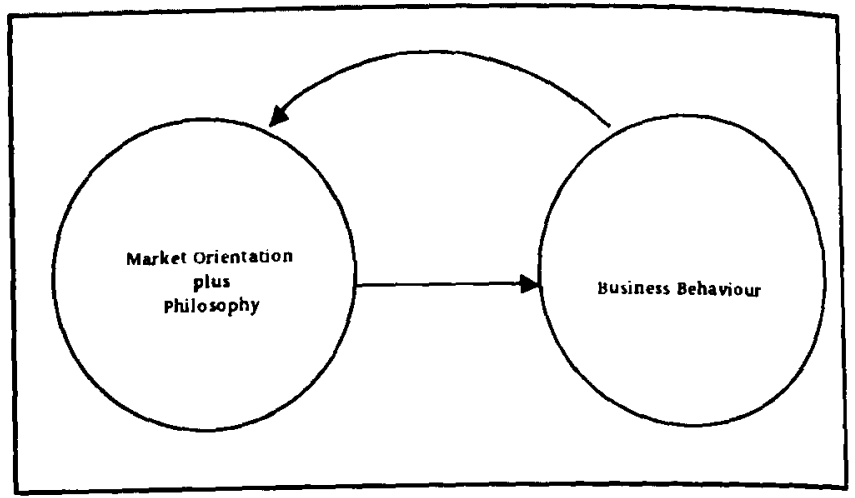

Figure 3 Market orientation construct

Philosophy in this model consists of two dimensions, namely business philosophy and market orientation.

Business philosophy in itself can be observed in the way the organisation

- continuously endeavours to create superior value for cus. tomers by reacting to market intelligence;

- focuses on achieving high ROE and good growth in total assets;

- communicates and treats their own employees, with both committed to the mission of the organisation;

- is focused on serving the needs of their customers through employees also committed to this;

- encourages innovative marketing strategies and ap proaches, based on frequent contact with customers; and

- top management continuously stressing the relationship between success and adapting to changing market needs.

Market orientation in itself can be observed in the way the organisation

- accepts/institutes formal mechanisms to create superior value for customers;

- focuses on developing long-term relationships with customers;

- is structured and work together across functional boundaries;

- targets specific customer segments based on market orientation;

- relies on marketing people achieving well-defined objectives;

- responds to market changes;

- disseminates information effectively throughout the organisation;

- benchmarks themselves to the competitors;

- rewards employees for satisfying changing customer needs;

- includes its commitment to the customer in its mission and objectives;

- aligns objectives and strategies across functional borders;

- shares information between marketing and technical people;

- controls the needs of the entire channel; and

- manages market intelligence effectively.

From the causal construct can be deducted that market orientation is inherently concerned with the philosophy of the organisation. However, market orientation appears to be more the manifestation of philosophy in the business. than the 
philosophy itself. This can be seen in manifestations such as attitude to strategic marketing. competitor focus, customer focus, interfunctional co-ordination and organisation structure/ systems. It is the organisation's culture, management philosophy and top management leadership that give focus to the organisation

\section{Impact of external variables on the organisation system}

External variables can have a direct or indirect impact on the business outcomes of the organisation. These impacts can also be positive or negative. While it is relatively easy to postulate the impact of an external variable on the performance of the organisation or on any specific dimension of market orientation, it is complex to measure. This is because an organisation is likely to adjust itself over time to minimise the effect of any external factor on its performance. Consequently, an external variable is likely to have different relevance to different organisations, even within the same industry.

The following external variables were tested in this study:

- Technology is changing rapidly.

- Customers product preferences are changing a lot over time.

- Customers are price sensitive.

- Competition is aggressive.

- Competitors are strong.

- The market is growing rapidly.

- Buyers have a lot of power.

It was found statistically that none of these external variables is significantly correlated with market orientation as a philosophy. Business behaviour. however, is significantly correlated with one external variable, namely: buyers have a lot of power

\section{Relationship between the organisation system of which market orientation is an element, and busi- ness performance}

An organisation has to achieve various outcomes in order to grow and prosper, but also to satisfy its stakeholders. While past performance is no guarantee of future performance. it provides some indication of the outcomes of certain behaviours. Seven indicators of financial performance were used in this study, namely:

- Growth in market capitalisation.

- Growth in total assets.

- Growth in equity.

- Return on equity.

- Return on assets.

- Growth in sales.

- Price earnings: organisation versus sector.

Only one performance measurement, return on equity, is significantly correlated with market orientation in its consolidated form. Business behaviour is significantly correlated with two performance measurements, namely: growth in total assets, and return on equity. It was found that organisations with a positive composite performance score (based on factor 1 as extracted with the principal components factor analysis technique) generally achieve higher values for the system dimensions than those with negative composite performance scores. It can therefore be concluded that the behaviour of organisations with higher levels of market orientation will lead to higher levels of business performance, especially in terms of return on equity and growth in total assets.

In testing the impact of external variables on performance measurements, a high level of correlation was established. Growth in total assets is correlated with technology changes and market growth. Return on equity is correlated with technology and price sensitivity of customers. Return on assets is correlated with price sensitivity, aggressive competition and strong competitors. Growth in sales is correlated with strong competitors and powerful buyers. Price earnings of the organisation versus price earnings of its sector is correlated with market growth.

\section{Conclusion}

Flowing from this research, market orientation can be defined as the organisation's business philosophy and culture that provide strategic directions for satisfying the needs of selected markets. It is focused on creating mutually rewarding relationships with customers, where

- the interests of all stakeholders are actively pursued;

-. competitive advantage is based on the organisation's ability to learn from the market and itself, and to mobilise core competencies in response:

- a set of beliefs exists that put the customer's interest first; and

- processes exist that support these beliefs.

In taking a strategic view of market orientation as a co-producer of business outcomes, the following interpretations can be articulated:

- Business outcomes are the results of everything that happen in the organisation and many things that happen outside the organisation. A market orientation, however important and fundamental, can at best only be a co-producer of business outcomes. This study shows that a market orientation as defined in this context, is indeed a necessary, but maybe not sufficient, condition for higher financial outcomes.

- A market orientation refers to creating superior value for stakeholders. While the outcome of this philosophy may not directly be visible in financial performance. especially in the short term, it should be measurable in terms of intermediate outcomes. Such intermediate outcomes could include customer satisfaction, employee satisfaction, customer retention, corporate image, product/service quality. and so forth.

- Business outcomes, especially in listed organisations, have powerful impact on the philosophy of the organisation. Adequate, positive and improving business results are likely to confirm and strengthen the prevailing business philosophy, whereas inadequate, negative and declining business results are likely to lead to the business philosophy being questioned and even changed.

- A higher market orientation contributes to higher levels of financial performance.

- From the study it became apparent that it would be difficult. and maybe even undesirable, to establish causal relationships between the sub-dimensions of philosophy and behaviour, and between the indicators of such dimensions. 
What is essential is that dimensions and indicators are assessed and viewed to ensure that they all fit into the definition of market orientation. Figure 4 shows the systemic perspective of market orientation as a co-producer of business outcomes.

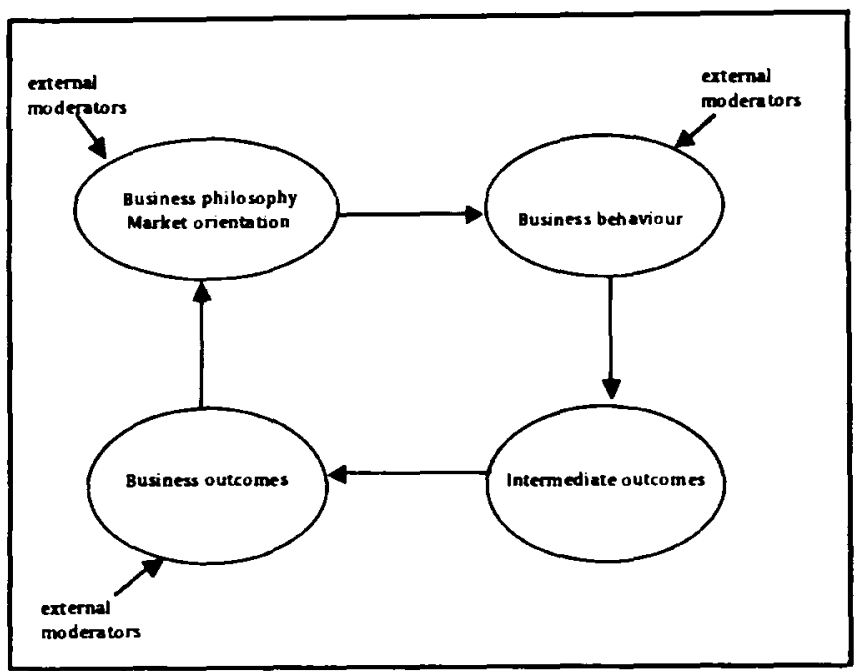

Figure 4 Systemic perspective of market orientation

While there are strong indications that a higher market orientation will lead to higher business outcomes, there is no definitive recipe that will provide such a causal relationship. Management should take a holistic view, focusing on the following issues:

- The strategy of the organisation should be formulated in terms of creating value for customers and stakeholders with a view of developing long-term relationships.

- A knowledge base should be developed and maintained on the market in terms of customer requirements, changing environmental trends and all other channel members including stakeholders and competitors.

- Mechanisms should be put into place to ensure that the organisation will learn from customers and markets.

Future research should be conducted in the following areas to obtain greater insight into the phenomenon of market orientation:

- market orientation as a business culture and philosophy;

- artefacts of a market orientation culture;

- behavioural patterns typical of a market orientation;

- intermediate outcomes of a market orientation; and

- market orientation as a necessary but also sufficient condition for business excellence and success in the longterm.

\section{References}

Argyris, C. 1977. Double loop learning in organisations, Harvard Business Review, September-October.
Brown, R. 1987. Marketing - a function and a philosophy, Quarterly Review of Marketing, 12(3): 25-30

Deal. T.E. \& Kennedy: A.A. 1982. Corporate cultures: the rites and rules of corporate life. Reading Massachusetts: Allison-Wesley.

Deshpandé. R. \& Webster. F.E. (Jr). 1989. Organisational culture and marketing: defining the research agenda, Journal of Market. ing. 53: 3-15.

Dreher. A. 1994. Marketing orientation: how to grasp the phenomenon. In Baker. M.J. ed. Perspectives on marketing management. New York: John Wiley \& Sons, pp. 149-170.

Garvin, D.A. 1993. Building a learning organisation, Harvard Business Review, July-August: 78-91

Greenley, G.E. 1995. Forms of market orientation in UK companies. Journal of Management Studies. 32: 47-66.

Hooley, G.J.. Lynch. J.E. \& Shepherd, J. 1990. The marketing concept: putting the theory into practice, European Journal of Marketing, 24(9): 7-24.

Hunt, S.D. \& Morgan, R.M. 1995. The comparative advantage theory of competition. Journal of Marketing. 59: 1-15

Kilmann. R.H. 1985. Gaining control of the corporate culture. San Francisco: Jossey-Bass Publishers

Kohli. A.K. \& Jaworski. B.J. 1990. Market orientation: the construct. research propositions, and managerial implications. Journal of Warketing. 54: 1-18.

Lichtenthal. J.D. \& Wilson. D.T. 1992. Becoming market oriented. Journal of Business Research. 24: 191-207.

Lusch, R.F. \& Laczniak. G.R. 1987. The evolving marketing concept, competitive intensity and organisational performance, Journal of the Academy of Marketing Science, 15(3): 1-11.

Narver, J.C. \& Slater, S.F. 1990. The effect of a market orientation on business profitability, Journal of Marketing, October: 20-35.

Olavarrieta, S. \& Friedmann. R. 1999. Market-oriented culture. knowledge-related resources, reputational assets and superior performance: a conceptual framework. Journal of Strategic 1tarketing. 7: 215-228.

Pascale, R.T.\& Athos, A.G. 1981. The art of Japanese management New York: Simon and Schuster.

Peters, T.J. \& Waterman, R.H. (Jr). 1982. In search of excellence. New York: Warner Books.

Quinn. R.E. 1988. Beyond rational management. San Francesco: Jossey-Bass Publishers

Schein. E.H. 1985. Organisational culture and leadership. San Francisco: Jossey-Bass Publishers.

Senge. P. 1990. The fifth discipline. New York: Currency Duubleday.

Sinkula. J.M. 1994. Market information processing and organisational learning. Journal of Marketing. Vol. 58: 35-45.

Slater, S.F. \& Narver. J.C. 1995. Market orientation and the learning organisation, Journal of Marketing, Vol. 59: 63-74.

Swartz. G.S. 1990. Organising to become market-driven. Cambridge, MA: Marketing Science Institute Repon. no. 90-123.

Tuominen. M. \& Möller. K. 1996. Market orientation: a state-ofthe-art review. Proceedings of the $25^{\text {th }}$ EMAC conference: Budapest. 1161-1181

Webster, F.E. (Jr) \& \& Deshpandé, R. 1990. Analysing corporate cultures in approaching the global marketplace. Cambridge. MA: Marketing Science Institute Report, no. 90-111.

Wilkens, A.L. 1983. The culture audit: a tool for understanding organisations. Organisational Dynamics, Autumn: $24-38$. 